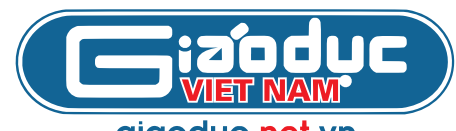

giaoduc.net.vn

Tạp chí điện tử Giáo dục Việt Nam

\title{
Trao đổi với Tiến sĩ Dương Văn Tú về khái niệm "giặc ngoại xâm trong khoa học"*
}

GDVN- Trong tiếng Việt, ngoại xâm tức là sự chiếm đoạt hoặc đánh phá đất đai do quân đội nước ngoài tiến hành ồ ạt, theo quy mô lớn.

04/09/2020 06:44 Phó giáo sư Phạm Thanh Phong

LTS: Ngày 01/9/2020, Báo Thanh niên có đăng bài viết "Thành tích ảo trong nghiên cứu khoa học: Các trường đại học Việt Nam có thể đang bị 'ăn thịt"', kêu gọi mọi người cùng nhau chống "giặc ngoại xâm khoa học".

Phó giáo sư Phạm Thanh Phong- Viện trưởng Viện tiên tiến khoa học vật liệu, Trường Đại học Tôn Đức Thắng có bài viết gửi tới tòa soạn Tạp chí điện tử Giáo dục Việt Nam trao đổi, phản biện một số vấn đề tác giả Dương Tú nêu.

Để đảm bảo khách quan, đa chiều nhằm làm sáng rõ vấn đề dưới góc độ khoa học, Tạp chí trân trọng giới bài viết của Phó giáo sư Phạm Thanh Phong. Văn phong và nội dung bài viết thể hiện quan điểm của tác giả, tiêu đề bài viết do Tòa soạn đặt.

Khoan nói đến vấn đề ngoại xâm khoa học, chỉ ngay việc thẩm định chất lượng nghiên cứu và năng lực nghiên cứu của một nhà khoa học cũng đã cần phải được đánh giá bởi các chuyên gia trong ngành mới có cái nhìn chính xác.

Chúng tôi nhận thấy bài viết của tác giả Tiến sĩ Dương Tú không xuất phát "khái niệm" và "bằng chứng"; những điều mà lẽ ra bất kỳ nhà nghiên cứu nào cũng phải hiểu.

Tác giả Tiến sĩ Dương Tú thuộc Đại học Purdue (Mỹ) theo tìm hiểu của chúng tôi, tên thật là Dương Văn Tú có học vị tiến sĩ về Dược và hiện đang làm nghiên cứu sau tiến sĩ tại Khoa dược thuộc đại học này.
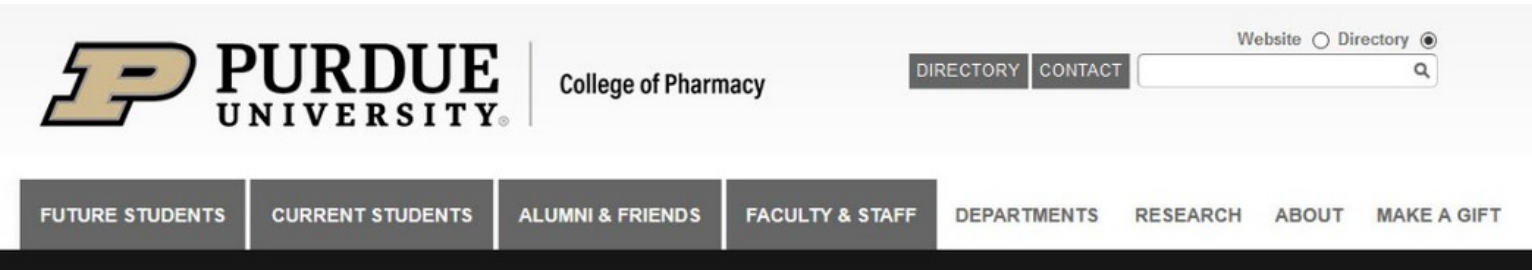

Directory > Van Tu Duong

\section{VAN TU DUONG}

$\begin{array}{ll}\text { Title(s): } & \text { Post-Doctoral Research Associate } \\ \text { Type: } & \text { Post Doctorial } \\ \text { Member of: } & \text { Dept of IPPH } \\ \text { Office: } & \text { RHPH G59 } \\ \text { Phone: } & 765-494-1693 \\ \text { Lab: } & \text { RHPH G59 } \\ \text { Lab phone: } & 765-494-1774 \\ \text { Fax: } & 765-494-6545 \\ \text { E-mail: } & \text { vduong@purdue edu凶 } \\ \text { Address: } & \text { Heine Pharmacy Building } \\ & \text { 575 Stadium Mall Drive } \\ & \text { West Lafayette, IN 47907-2091 }\end{array}$

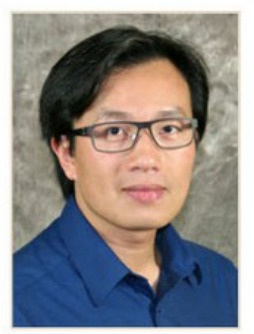

Tiến sĩ Tú hiện có 6 công trình ISI về Dược: 


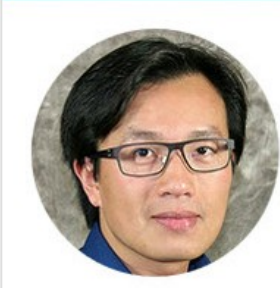

\section{Tu Van Duong}

Web of Science ResearcherID (2)

Postdoctoral Fellow - Industrial and Physical Pharmacy, Purdue University

\begin{tabular}{l|l|l|l} 
PUBLICATIONS & TOTAL TIMES Cited & H-INDEX & VERIFIEd REVIEWS \\
\hline 6 & &
\end{tabular}

\begin{tabular}{l|l|l|l}
6 & 115 & $5^{\circ}$ & 17
\end{tabular}

HI Summary

il. Metrics

N Publications

Q. Peer review

\section{Research Fields}

AMORPHOUS SOLID DISPERSIONS CRYSTALLIZATION DRUG DELIVERY DRUG DELIVERY SYS DRUG FORMU FORMULATION INDUSTRIAL PHARMACY PHARMACEUTICAL FORMULATION RESEARCH \& DEVELOPMENT PHARMACEUTICAL INDUS PHARMACEUTICAL SCIENCE PHARMACEUTICAL SCIENCES

+ VIEW FULL BIO \& INSTITUTIONS

Trong đó công trình mới nhất được Tiến sĩ Dương Văn Tú công bố trong năm 2018 và trong khoảng 2 năm qua không có công bố nào mới.

Hơn nữa, chúng tôi thực sự quan ngại khi Tiến sĩ Tú lại bàn về các khía cạnh hợp tác khoa học và quản lý khoa học khác nhau, nhưng đọc hết cả bài viết, chúng tôi nhận ra rằng các khái niệm, bằng chứng tác giả đưa ra rất hạn chế về những vấn đề mà mình đang đề cập.

Trong tiếng Việt, ngoại xâm tức là sự chiếm đoạt hoặc đánh phá đất đai do quân đội nước ngoài tiến hành ồ ạt, theo quy mô lớn.

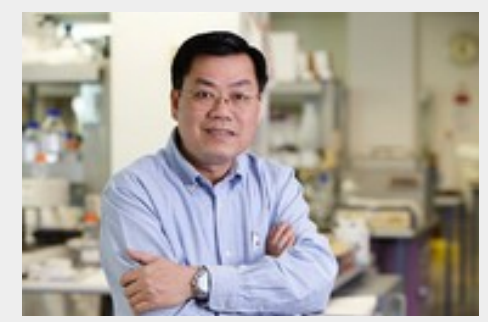

Bài báo khoa học là một thành quả tri thức, sao lại dùng từ "mua- bán"?
Hành động hợp tác của các nhà khoa học nước ngoài có nhiều công bố như vài trường hợp điển hình mà bài báo nêu ra với các trường Đại học của Việt Nam thông qua một hợp đồng làm việc đúng luật có thể gọi là "ngoại xâm" hay không? chúng tôi nhận thấy nhận định này không ổn.

Thay vì xem xét, đánh giá chất lượng các công trình của các nhà khoa học này, lại quay sang đả kích họ với một lý do rất đơn giản là do công bố quá nhiều; trong khi bản thân tác giả cũng không thể có năng lực để đánh giá chất lượng các công trình ấy.

Tác giả đưa nhận xét: "Không một nhà khoa học bình thường nào mỗi năm có thể công bố hằng trăm công trình thuộc đủ mọi lĩnh vực, cả tính toán lý thuyết lẫn thực nghiệm, từ khoa học chính trị, toán học, dược học đến khoa học vật liệu, vật lý thiên văn, khoa học máy tính (hết trích)".

Nhưng năm 2018, Tập san Nature đã có một bài báo tựa đề: "Thousands of scientists publish a paper every five days" [1] , trong đó chỉ ra hàng ngàn nhà khoa học có tốc độ xuất bản 5 ngày/1 bài báo.

Trong giai đoạn từ năm 2000 đến năm 2006 có đến 30 nhà khoa học xuất bản trên 1000 ấn phẩm, tức là bình quân mỗi năm có trên 150 bài. Một năng suất làm việc phi thường!

Điển hình như các nhà khoa học: Shizuo Akira, Đại học Osaka, Nhật Bản với 1003 bài; Jeroen J. Bax, Đại học Leiden, Hà Lan với 1134 bài;

Frede Blaabjerg, Đại học Aalborg, Đan Mạch với 1117 bài; Markus W. Büchler, Đại học Heidelberg, Đức với 1018 bài; 
Luigi Ferrucci, Viện nghiên cứu quốc gia về Khoa học sức khỏe (U.S. National Institutes of Health), Hoa Kỳ với 1042 bài;

Ray L. Frost, Đại học kỹ thuật Queensland, Úc với 1043 bài; Hoong-Kun Fun, Đại học King Saud, University, Ả-Rập Xê-út với 1678 bài;

Soares C. Guedes, Instituto Superior Tecnico Lisboa, Bồ Đào Nha với 1081 bài; Albert Hofman, Erasmus University Rotterdam, Hà Lan với 1561 bài;

Akihisa Inoue, Đại học Tohoku University, Nhật Bản với 1680 bài; Hagop Kantarjian, Đại học Texas, Hoa Kỳ với 1290 bài;

Gregory Y.H. Lip, University of Birmingham, Vương quốc Anh với 1407 bài; Klaus Müllen, Viện Max Planck, Đức với 1245 bài;

Seik Weng Ng, University of Nottingham Malaysia Campus với 1476 bài; Andreas Tünnermann, Fraunhofer - BY-THSN, Đức với 1439 bài; Didier Raoult, Universite de la Mediterranee Aix-Marseille II, Pháp với 1205 bài.

Đặc biệt kể từ năm 2006, khi các "siêu tạp chí-mega journal" ra đời như PLOS ONE (Hoa Kỳ), và sau đó là Scientific Reports (Nature, Hoa Kỳ) và nhiều tạp chí khác thì các công trình nghiên cứu đa ngành, đa lĩnh vực xuất hiện ngày càng nhiều hơn; và số lượng các nhà khoa học tham gia vào các công trình đa ngành cũng ngày càng lớn.

Đặc điểm của các "siêu tạp chí" này là tỷ lệ chấp nhận bài cao (khoảng 50\% bản thảo được gửi đến) và không quá nhấn mạnh vào tính mới, các nghiên cứu lặp lại hoặc kết quả chưa rõ ràng cũng được chấp nhận, các yếu tố mà các tạp chí khoa học truyền thống thường từ chối.

Các tác giả châu Âu thường xem các tạp chí này là một trong những lựa chọn thích hợp để công bố bởi họ thường nhận yêu cầu từ phía cơ quan tài trợ là sau khi xuất bản, tất cả mọi người đều có thể đọc được các công trình này miễn phí.

Tại Việt Nam, nếu để ý chúng ta cũng có thể quan sát nhiều nhà khoa học đã bắt đầu nghiên cứu theo chiều hướng này, đơn cử như nhà nghiên cứu Vương Quân Hoàng, Đại học Phenikaa trong năm 2019 theo thống kê chưa đầy đủ đã có gần 80 bài công bố trên các lĩnh vực khác nhau, từ Khoa học môi trường, Thống kê, Khoa học quản lý, Giáo dục, Truyền thông, Y tế công cộng, Quan hệ quốc tế, Xã hội học, ...nhà nghiên cứu Huỳnh Lưu Đức Toàn, Đại học kinh tế Thành phố Hồ Chí Minh, trong 6 tháng đầu năm 2020 đã có hơn 30 công trình nghiên cứu trên các lĩnh vực khác nhau từ Khoa học môi trường, Khoa học quản lý, Kinh tế, Khoa học an toàn, Y tế công cộng, Chính sách, Tâm lý, Khoa học Dữ liệu,...

Do đó chúng tôi cho rằng nhận định trong bài viết của Tiến sĩ Tú phiến diện, võ đoán, và chủ quan; đã phủ định sạch trơn công sức của các nhà khoa học nghiên cứu đa ngành, đa lĩnh vực.

Tất cả "bằng chứng" mà tác giả bài báo trưng ra dường như chỉ để quy chụp các nhà nghiên cứu (ghi trong bài báo đã dẫn) đã và đang ký hợp đồng làm việc với Trường đại học Tôn Đức Thắng, Trường Đại học Duy Tân là "mạng lưới mafia khoa học của những gã đầu nậu săn mồi", khi không nắm rõ thực tiễn nghiên cứu của thế giới, chưa tìm hiểu kỹ bằng chứng mà đã kết luận như vậy.

Mặt khác nếu nhìn vào danh sách bài báo bị rút (retract) của các nhà khoa học trên, có thể thấy kể từ khi ký hợp đồng làm việc cho trường Đại học Tôn Đức Thắng và trường Đại học Duy Tân, các nhà khoa học này chưa hề có bài nào bị rút cả. Do đó không thể kết luận là họ đã từng bị chuyện này, thì khi sang đơn vị khác họ cũng như thế.

Một khi trường Đại học Tôn Đức Thắng hay trường Đại học Duy Tân đẩy mạnh hợp tác trong nghiên cứu khoa học thì việc bị lạm dụng là không thể tránh khỏi. Nhưng giống cam đem trồng ở Sở thì chua nhưng sang Tề lại ngọt, bởi tại trường Đại học Tôn Đức Thắng hiện đang thực hiện nhiều biện pháp khoa học với một quy trình chặt chẽ để hạn chế đến mức thấp nhất những rủi ro không đáng có khi thẩm định một công trình khoa học. 
Ngay từ ban đầu đề ra chính sách công bố khoa học, trường Đại học Tôn Đức Thắng đã đưa các tạp chí "ăn thịt" hay kém chất lượng (dù các tạp chí này vẫn nằm trong danh mục ISI hoặc Scopus) vào danh sách không được trường Đại học Tôn Đức Thắng công nhận.

Tiến sĩ Tú chưa từng biết chính sách nghiên cứu khoa học của trường Đại học Tôn Đức Thắng nhưng lại cho rằng trường Đại học Tôn Đức Thắng đã phải chi cho hàng trăm công trình của một tác giả. Đó là trường hợp Tiến sĩ Kittisak Jermsittiparsert, đã ký hợp đồng làm việc với trường Đại học Tôn Đức Thắng từ năm 2018 và đến nay chỉ công bố 55 công trình ISI:

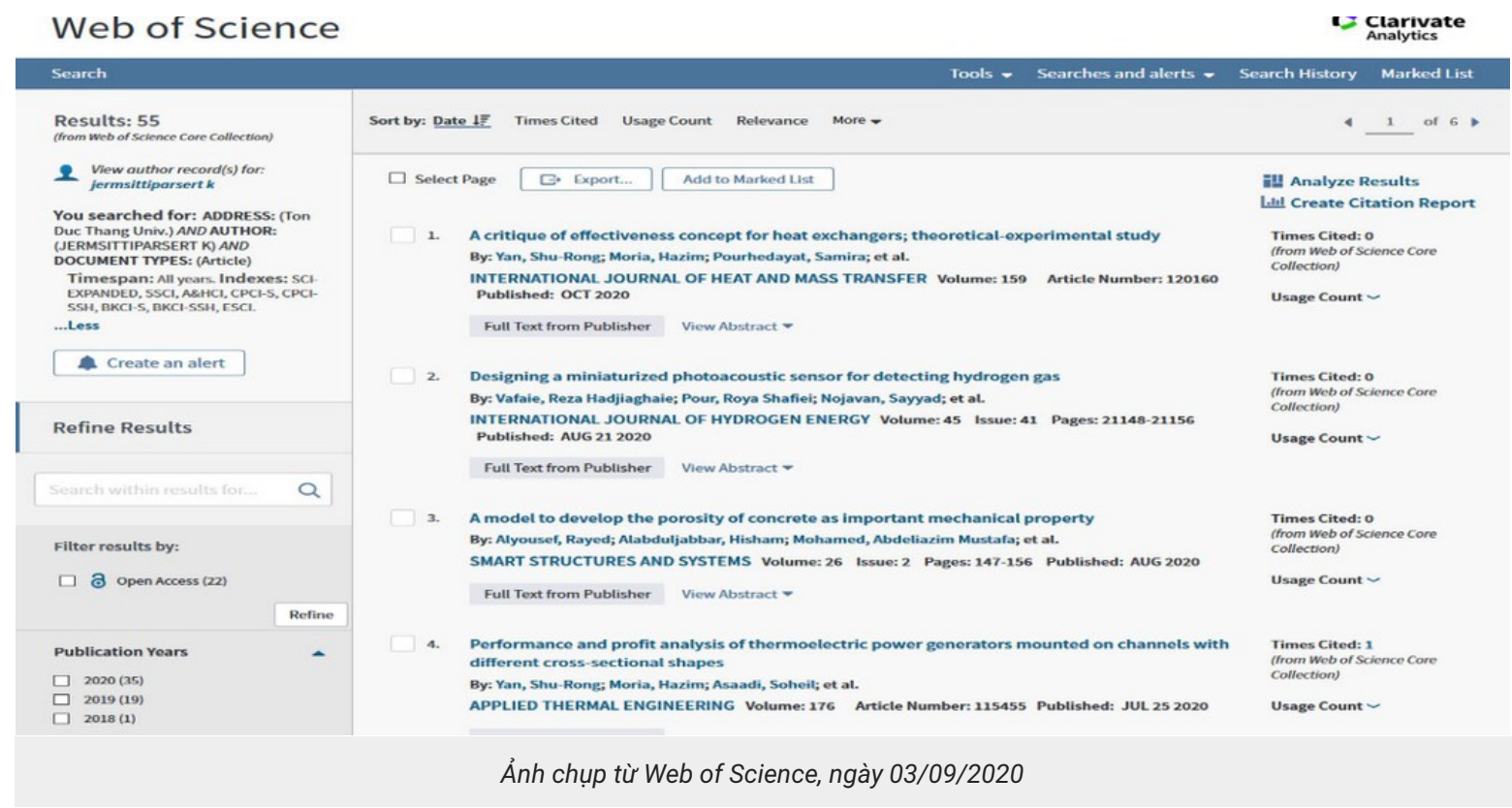

Ngoài ra, Tiến sĩ Jermsittiparsert cũng đã tự công bố nhiều công trình Scopus, và rất nhiều công trình Scopus trong số đó đã không được trường Đại học Tôn Đức Thắng nghiệm thu (do không đúng sản phẩm như đã đăng ký).

Việc công bố nhiều công trình Scopus không thuộc diện ưu tiên của trường Đại học Tôn Đức Thắng. Scopus được xếp hạng thấp nhất trong trường Đại học Tôn Đức Thắng Journal Rankings. Nghiên cứu viên công bố một công trình Scopus tác giả chính thì lương nghiên cứu là 1.6 triệu/tháng (chưa kể các chỉ số khác) nhưng tổng không nhiều.

Xét thấy việc hợp tác với Tiến sĩ Jermsittiparsert không có hiệu quả như mong đợi và rất khó để Tiến sĩ Jermsittiparsert có thể tham gia đội ngũ cơ hữu hùng mạnh của trường Đại học Tôn Đức Thắng, nên trường Đại học Tôn Đức Thắng không tiếp tục sự hợp tác này. Và đương nhiên, Tiến sĩ Jermsittiparsert cũng đã bị chất vấn bởi Chương trình tầm soát công bố khoa học của trường Đại học Tôn Đức Thắng.

Trường Đại học Tôn Đức Thắng chủ yếu dùng cơ sở dữ liệu WoS (Mỹ) để tra cứu các công trình ISI. Chúng tôi không dùng hoặc ít dùng Scopus vì chúng tôi thấy hầu hết những tập san ISI thì uy tín hơn.

Tiến sĩ Tú đã không hiểu điều này vì chưa bao giờ có trao đổi với trường Đại học Tôn Đức Thắng trước khi đưa thông tin.

Vấn đề thứ hai là có nên hạn chế chủ đề nghiên cứu của các nhà khoa học không?

Hiện nay khoa học ngày càng đi sâu vào việc giải quyết những vấn đề đa ngành, cho nên đang rất cần các nhà khoa học có sự hiểu biết rộng; chẳng hạn trong các ngành thuộc Khoa học và kỹ thuật nano, các ứng dụng của chúng trong y sinh rất cần một nhà khoa học vừa có kiến thức sâu về Vật lý, Hóa học, Khoa học Vật liệu và Y sinh.

Do đó, việc một nhà khoa học được đồng thời xếp vào các lĩnh vực nghiên cứu khác nhau là bình thường.

Mặt khác cách phân loại này còn phụ thuộc vào từng cơ sở dữ liệu nữa. 
Chẳng hạn phạm vi công bố của tạp chí Journal of Chemical Information and Modeling của ACS là Medicinal Chemistry, Multidisciplinary Chemistry, Computer Science; thì Scopus lại xếp vào Chemical Engineering, Chemistry, Computer Science và Social Science.

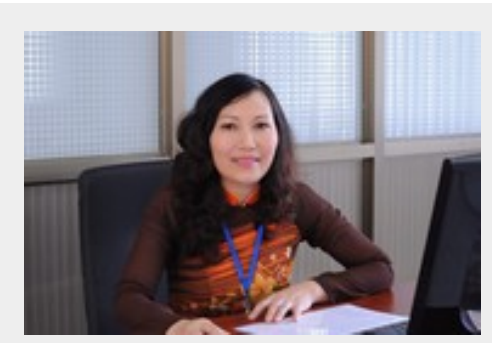

Bí quyết nào giúp Đại học Tôn Đức Thắng có nhiều bài báo khoa học ISI?
Trên cơ sở tham khảo các mô hình tiên tiến trên thế giới, các vụ vi phạm hoặc nghi ngờ có dấu hiệu vi phạm trong nghiên cứu khoa học tại Trường Đại học Tôn Đức Thắng đều được xem xét và xử lý triệt để bởi Ủy ban đạo đức nghiên cứu bao gồm các chuyên gia trong cùng lĩnh vực nhà nghiên cứu bị đưa ra xem xét, chứ không phải kéo nhau lên các diễn đàn công cộng, bởi xem xét đánh giá việc này phải thực sự khách quan, không bị cảm tính chi phối và có chuyên môn gần với nhà nghiên cứu.

Tại cuộc họp này, các nhà khoa học đối thoại công khai với đầy đủ bằng chứng để phân tích, đánh giá chính xác từng vụ việc cụ thể.

Việc phân xử trong nghiên cứu khoa học phải là công việc của các hội đồng chuyên môn gồm các chuyên gia có nhiều kinh nghiệm trong nghiên cứu khoa học hoặc quản lý khoa học, hơn là những ý kiến cảm tính trên truyền thông.

Đây là cách hành xử của Trường Đại học Tôn Đức Thắng vừa đúng theo thông lệ quốc tế, vừa nhân văn bởi vì giả dụ họ có sai; thì vẫn còn cơ hội để sửa sai và làm lại.

Trường Đại học Tôn Đức Thắng tự hào là đã có nhiều chính sách tích cực về công bố khoa học xuyên suốt trong kế hoạch 30 năm và được cụ thể hóa trong từng kế hoạch 5 năm và từng năm.

Trong mỗi kỳ kế hoạch đều xây dựng chi tiết cho các loại hình nghiên cứu, các chính sách tuyển dụng chuyên gia, tuyển dụng các nhà khoa học, xây dựng nội lực, xây dựng phòng thí nghiệm nhằm bảo đảm cho các nhà khoa học đủ sống và có môi trường nghiên cứu đạt chuẩn quốc tế.

Trường Đại học Tôn Đức Thắng đã ký hợp tác với nhiều tổ chức và Đại học nước ngoài và nhờ họ tư vấn nhiều chính sách có liên quan không chỉ đến chính sách phát triển khoa học mà còn cả xây dựng một môi trường học thuật, giảng dạy lành mạnh, tiên tiến.

Do đó, đã góp phần kích thích các nhà khoa học trong nước công bố trên các tạp chí ISI. Chúng tôi ý thức rằng trên con đường phát triển, không thể không có sai sót, do đó chúng tôi rất cầu thị lắng nghe ý kiến xây dựng của các bậc thức giả nhằm làm cho sự phát triển của Trường Đại học Tôn Đức Thắng ngày càng tốt hơn.

\section{Tài liệu tham khảo:}

[1] https://www.nature.com/articles /d41586-018-06185-8?fbclid=IwAR0bOY2BgEeJIYp2GOnwxzW2hLrpjxBuloWoicrm_X44SVb5BBAzT-eUqN4

[2] https://www.sciencemag.org/news/2019/09/open-access-megajournals-lose-momentum-publishing-modelmatures

[3] https://scholar.google.com/citations?hl=en\&user=JURGXJUAAAAJ\&view_op=list_works\&sortby=pubdate\& fbclid=IwAR16jzVXkTb4XiJEN5kmvwIgUGIG9PaP_eFVpPB1pXew9RUWJfZocMDb-jg

[4] https://scholar.google.com/citations?user=UaW1TOAAAAJ\&hl=vi\&

fbclid=IwAR1 uyKtPmdswoa1ANuueBS01 wIGIz0MEeYN2BeFfvYjFx_IhSB8AnzbqT0s

[5] https://vi.wikipedia.org/wiki/Y\%E1\%BA\%BFn_Anh 
https://giaoduc.net.vn/tin-hiep-hoi/trao-doi-voi-tien-si-duong-van-tu-ve-khai-niem-giac-ngoai-xamtrong-khoa-hoc-post212131.gd

(C2020 GDVN 